\title{
DIREITOS AUTORAIS E INTERNET: DO CONTEUDO AO ACESSO
}

\section{Ursula Blattmann \\ Gregório Jean Varvakis Rados}

RESUMO: Resgata abordagens sobre direitos autorais na Internet. Apresenta questões referentes ao conteúdo e ao acesso à informação na Internet. Enfoca a legislação brasileira a ser observada pelo bibliotecário atuante no ciberespaço: os direitos autorais, a propriedade intelectual e ética na informação. Ponderações sobre acesso e liberdade de informação digital online.

PALAVRAS-CHAVE: Direitos autorais; Internet; Propriedade intelectual; Acesso à informação.

\begin{abstract}
Questions about the copyright issues in the Internet, the contends and access information in the Web. Librarians need to considerate the Brazilian law in the cyberspace: copyright, intellectual property and information ethics. Reflection about the intellectual freedom and access to digital information online.
\end{abstract}

KEY-WORDS: Copyright, Intellectual property, Information Access. 


\section{DIREITOS AUTORAIS NA INTERNET}

A temática sobre direitos autorais é pertinente nos ambientes em que haja um fluxo da informação - tradicional ou digital. Certamente necessita-se cada vez mais discutir, seja em fóruns específicos ou em canais disponíveis, indiferente dos ambientes (impresso ou digital).

Os debates necessitam serem aprofundados envolvendo aspectos sobre os direitos autorais, a propriedade intelectual e a ética na informação. É fundamental que seja reconhecida a importância do trabalho intelectual e defender os interesses, sejam eles profissionais, sociais, culturais ou pessoais.

No CIBERETICA, realizado em novembro de 1998, promovido pela Associação Catarinense de Bibliotecários, foram discutidos esses temas que envolvem a questão dos direitos autorais. Nos anais, disponíveis online (http://www.ciberetica.iaccess.com.br/portug ues/anais.htm), observa-se trabalhos e palestras fundamentais para nortear alguns limites do ciberespaço, tais como apresentados no quadro 1:

QUADRO 1: Direitos autorais, propriedade intelectual e ética na informação: Ciberética - 1998.

\begin{tabular}{|c|c|}
\hline Autor & Título \\
\hline Renato Janine Ribeiro & Direito e ética na sociedade da informação (doc ${ }^{d}$ ) \\
\hline Hildebrando Pontes Neto & A legislação brasileira sobre direito autoral (ppt) \\
\hline José de Oliveira Ascenção & Direitos autorais na Internet (doc) \\
\hline Victor Montiviloff & Ethical and societal chalenges of cyberspace (doc) \\
\hline Esteban Valenti & $\begin{array}{l}\text { Ética, sociedad de la información y comércio electrónico } \\
\text { (doc) }\end{array}$ \\
\hline Luiz Fernando Martins Castro & $\begin{array}{l}\text { A Internet como meio de distribuição da informação } \\
\text { jurídica: O projeto AASP Internet (doc) }\end{array}$ \\
\hline $\begin{array}{l}\text { Vicente Landim de Macedo } \\
\text { Filho }\end{array}$ & Lei de Software: Propriedade Intelectual x Internet (ppt) \\
\hline José Adércio Sampaio & Limites éticos do uso da informação (doc) \\
\hline Jane Pinho & $\begin{array}{l}\text { Propriedade Intelectual: Adequação da Legislação } \\
\text { Nacional (ppt) }\end{array}$ \\
\hline $\begin{array}{l}\text { José Rincon Ferreira / Kira } \\
\text { Tarapanoff }\end{array}$ & $\begin{array}{l}\text { Sociedade da informação: conteúdos informacionais } \\
\text { (doc) }\end{array}$ \\
\hline Gilberto Martins de Almeida & Software e Internet: Proteção e regulamentação (doc) \\
\hline
\end{tabular}

Resgatando sucintamente o conteúdo abordado:

- legislação sobre software (Lei 9609/98), direitos autorais na Internet: as leis 9610/98 e legislação de propriedade intelectual envolvendo marcas e patentes (9276/96);
- nomes e a formação de nomes de domínios Internet e a atuação do Comitê Gestor Internet do Brasil (portaria MCT/MC 147/95 e resolução 001/98);

- direitos autorais e o comércio eletrônico;

- a problemática do direito autoral, a análise técnica sobre direitos de reprodução. A lei brasileira se afasta das

\footnotetext{
${ }^{1}$ Nota de esclarecimento: doc eqüivale a arquivo de documentos no Word; e, ppt significa um arquivo de apresentação para o Power Point. Softwares registrados da empresa Microsoft.
} 
leis internacionais sobre a lei de publicação. Provocando polêmicas da lei no que se refere a sua interpretação. Como recomendação proposta: impor mais responsabilidade ao provedor de serviços sobre o material que se disponibiliza na Internet.

- a sociedade da informação representa o apogeu da informação. Situação de afunilamento da informação. Redução de canais verdadeiros. $\mathrm{O}$ direito da informação fica cada vez mais limitado. A informação está deixando de ser livre. Manipulação da informação. Desenvolvimento tecnológico - a sua utilização será realizada pelas pessoas. $\mathrm{O}$ que interessa é o uso destas informações. (este tópico apresentado por José de Oliveira Ascensão)

As diferentes colocações dos palestrantes e conferencistas são interessantes e, mesmo passados dois anos, essa temática (direitos autorais na Internet) continua a preocupar os envolvidos direta ou indiretamente pela informação disponibilizada nas redes de computadores.

Sem dúvida a Internet continua a crescer exponencialmente, e problemas antes inexistentes hoje assolam o cotidiano do bibliotecário. Ele passa a utilizá-la cada vez mais, agregando valor aos serviços desenvolvidos. Aos poucos essa tecnologia Internet - está sendo disseminada de tal forma, que em muitos casos já não se imagina como seria viver sem ela.

Assim, questões sobre o que é legal, ilegal, possível e dificultoso vão atormentando o profissional bibliotecário no emaranhado mundo das redes de computadores. Para conseguir entender estas mudanças, necessita ser observado a crescente importância que ocorre na literatura referente às implicações sobre o uso dos conteúdos disponibilizados na Internet, e, principalmente na prática do cotidiano biblioteconômico que auxiliam em resolver, diminuir ou até contornar determinados problemas em particular os aspectos legais inerentes ao acesso e disseminação da informação no ciberespaço. .

\section{A LEGISLAÇÃO NO CIBERESPAÇO E OS DIREITOS AUTORAIS: UM ENFOQUE EDUCACIONAL}

As mudanças decorrentes das tecnologias digitais necessitam ser analisadas e tratadas sob enfoque dos aspectos legais e profissionais nas diferentes áreas interdisciplinares do conhecimento e principalmente aos envolvidos no campo da educação. Questões sobre os direitos autorais, copyright e concessão de licenças para o uso de materiais digitais na educação presencial e a distância precisam ser esclarecidas, pois são vitais para aquisição, armazenamento e disseminação dos diferentes tipos de publicações em bibliotecas e, mais especificamente, no acesso e entrega de documentos eletrônicos e digitais na educação a distância.

Martins Filho (1998, p. 183, 187) menciona que os "direitos autorais lidam basicamente com a imaterialidade, principal característica da propriedade intelectual. Estão presentes nas produções artísticas, culturais, científicas etc. (...). "O importante a ressaltar é que todas as obras intelectuais (livros, vídeos, filmes, fotos, obras de artes plásticas, música, intérpretes etc.), mesmo quando digitalizadas, não perdem sua proteção, portanto não podem ser utilizadas sem prévia autorização."

O documento básico "Report on copyright and digital distance education" (http://lcweb.loc.gov/copyright/cpypub/de_rpt .pdf), elaborado pelo escritório de copyright dos Estados Unidos, fornece uma visão geral da natureza da educação a distância na atualidade, descreve as práticas correntes do uso de licenças na educação a distância digital, incluindo problemas e tendências futuras; relata o estado da tecnologia disponível ou em desenvolvimento, relacionado na entrega de cursos na educação 
a distância, e a proteção de seus conteúdos; discute iniciativas prioritárias sobre questões de copyright por meio da negociação das guias (guidelines) ou da legislação vigente.

Harper (1999) considera os diferentes aspectos sobre direitos autorais e propriedade intelectual e disponibiliza as informações online sobre "Copyright Law for Distance Learning", abordando, entre outros aspectos, questões voltadas à educação a distância: uso de materiais de arquivos e coleções especiais encontrados na Internet, digitalização de imagens analógicas; incorporando imagens em novos trabalhos; integração de diferentes tipos de trabalhos multimídia; e criando trabalhos derivados.

A jurisdição sobre copyright observa a legislação de cada país e deve ser respeitada e protegida pela maioria de outros países que são signatários da Convenção de Berna. A Convenção de Berna proporciona proteção recíproca aos trabalhos de copyright de outros países.

Devido à abrangência existente entre as questões de direitos autorais, copyright, licenciamento de uso, patentes e propriedade intelectual, as organizações internacionais estão permanentemente discutindo e buscando soluções por intermédio de regulamentos, leis e orientações reconhecidas e aceitas internacionalmente.

Alguns destes endereços a seguir oferecem base para o entendimento da importância, das diretrizes e dos requisitos das instituições que trabalham a questão da propriedade intelectual, direitos autorais, e de acesso à informação estão:

- Organização Mundial de Propriedade Intelectual - $\quad$ OMPI (http://www.ompi.org/),

- Escritório Europeu de Patentes - EPO (http://www.european-patent-

office.org/index.htm);

- Instituto Nacional da Propriedade Industrial $\quad$ - INPI (http://www.inpi.gov.br/),
- Legislação Brasileira (http://bdtextual.senado.gov.br/bdcoi/l egbra/legbra.htm);

- Fundação Biblioteca Nacional - BN (http://www.bn.br);

- Escritório de Direitos Autorais EDA(http://www.udesc.br/udesc/eda/) ;

- Câmara Brasileiro do Livro - CBL (http://www.cbl-net.com.br/cbl.htm).

No Brasil a legislação que visa a proteger a produção intelectual, garantindo aos titulares de produtos tecnológicos e intelectuais o resguardo de direitos e, inclusive, a percepção de frutos que possam ser por estes proporcionados, a seguir resumida em:

- Constituição Federal - art. 5º inciso XXVII: "aos autores pertence o direito exclusivo de utilização, publicação ou reprodução de suas obras, transmissível aos herdeiros pelo tempo que a lei fixar;" inciso XXIX: "A lei assegurará aos autores de inventos industriais privilégio temporário para sua utilização, bem como proteção às criações industriais, à propriedade das marcas, aos nomes de empresa e a outros signos distintivos, tendo em vista o interesse social e o desenvolvimento tecnológico e econômico do País";

- Lei n. 9.610, de 19 de fevereiro de 1998 (revogando a Lei de n. 5.988, de 14 de dezembro de 1973), que altera, atualiza e consolida a legislação sobre direitos autorais e dá outras providências;

- Lei n. 9.609, de 19 de fevereiro de 1998 (substitui a Lei 7.646/87), dispõem sobre a proteção de propriedade intelectual de programa de computador e sua comercialização no Brasil;

- Lei sobre propriedade industrial, $\mathrm{n}$. 9.279/96, de 14 de maio de 1996, apresenta os direitos e obrigações relativos à propriedade industrial; direitos autorais (Lei $n^{\circ}$ 9.610, de 19.2.98); 
- Lei n. 9.456, de 25 de 28 abril de 1997, sobre cultivares. Regulamentada pelo Decreto 2.366, de 5 de novembro de 1997, institui a proteção de propriedade intelectual referente a cultivares; e,

- Lei de Bio-segurança n. 8.974/95. Dispõe sobre o uso de técnicas de engenharia genética e liberação de organismos modificados no meio ambiente.

Aos envolvidos direta ou indiretamente com publicações nos seus diferentes formatos, recomenda-se estudar claramente a abrangência e profundidade da legislação que aborda os direitos autorais. São condicionantes que repercutem na elaboração de cursos e programas de educação sejam presenciais ou a distância e principalmente no uso, reprodução e entrega de documentos envolvendo, entre outros, o material bibliográfico, didático-pedagógico e acesso a bases de dados.

Nos diferentes artigos da Lei n. 9.610, cabe conhecer profundamente os aspectos referentes: a autoria, a autorização prévia e expressa do autor para a utilização da obra, por quaisquer modalidades, tais como: reprodução parcial ou integral; edição; a adaptação, o arranjo musical e quaisquer outras transformações; a tradução para qualquer idioma; a distribuição, quando não intrínseca ao contrato firmado pelo autor com terceiros para uso ou exploração da obra; a distribuição para a oferta de obras ou produções mediante cabo, fibra ótica, satélite, ondas ou qualquer outro sistema que permita ao usuário realizar a seleção da obra ou produção para percebê-la em um tempo e lugar previamente determinados por quem formula a demanda, e nos casos em que o acesso às obras ou produções se faça por qualquer sistema que importe em pagamento pelo usuário; a inclusão em base de dados, o armazenamento em computador, a microfilmagem $e$ as demais formas de arquivamento do gênero.

Frey (1997) relata que a transição do material impresso para o digital tem sido problemática tanto aos criadores de propriedades materiais, bem como aos seus usuários. Emergem novos modelos legais e econômicos de tratamento dos objetos tradicionais físicos, tais como livros e periódicos, e incorporando novas formas de pagamento para as licenças de uso da propriedade intelectual no ambiente da informação digital em rede de computadores.

Entre seus argumentos, Frey (1997) menciona o conflito dinâmico existente no ciberespaço, pois o histórico da cultura Internet desenvolveu-se pelo uso cooperativo e tende-se a definir o trabalho digital como "gratuito". As facilidades de obter informações pela Internet proporcionam debates sobre os direitos autorais e de copyright, quando se pode utilizar informações de uso público e, aparentemente, de acesso gratuito do material digital na rede.

Analisando a legislação e o mercado informacional, Frey (1997, p. 29) destaca que estão emergindo diversos novos modelos no comércio digital. Relacionando em seu artigo seis destes modelos, salientando que são caracterizados pelo uso das novas tecnologias e cujas raízes estão voltadas aos aspectos econômicos da entrega da informação. Esses modelos são: o Website "gratuito"; de controle de circulação; de subscrição; de publicidade subsidiada; transacionais; e de Broadcast (tecnologias de push e pull).

Portanto, o mercado de publicações reagiu e encontrou alguns diferentes modelos de comercialização e controle da informação digital online. Certamente, os bibliotecários terão que verificar quais as soluções mais propícias para atender seus usuários.

Entre as reações sobre soluções que despontam na Internet, observa-se a convergência de papéis: autor - publicador distribuidor. Onde o autor escolhe em qual ambiente publicar, realizar a diagramação, define a capa de sua publicação e disponibiliza na rede de computadores para download de quem quiser. E isto tudo ocorre 
em ambientes de alta velocidade e a custos financeiros baixíssimos.

$\mathrm{Na}$ palestra proferida por Hoeschel (2000), nota-se como está cada vez mais fácil e prático publicar e manter o controle sobre o produto intelectual digitalizado e disponibilizado na rede de computadores. Exemplificando em que o autor realiza as tarefas de escolher qual o canal para publicar, tal como acontece na Biblioteca Rocket (http://rocket-library.com). Os e-books tornam-se uma realidade do cotidiano do usuário final. Por exemplo, o leitor pode realizar o download do software $\mathrm{e}$ as respectivas publicações no formato do $e$-book e lê-las; e também disponibilizar seu livro no respectivo formato e disponibilizá-lo na Web para todos. Verifica-se nesses casos mudanças nas etapas tradicionais do ciclo da informação, uma intensa interação por parte do usuário e facilidades na disseminação e acesso da informação digital online.

Nesse sentido o profissional da informação necessita acompanhar a evolução constante da tecnologia que possibilita novas formas de publicação, interação, disseminação e recriação da informação.

As novas tecnologias oriundas da área de tecnologia da informação, cada vez mais incrementadas, podem tanto auxiliar como também dificultar o acesso e disseminação da informação digital online. São dispositivos que os bibliotecários necessitam conhecer e utilizar no sentido de preservar a propriedade intelectual, os direitos autorais, de licenciamento e uso, e de copyright.

Considerando as inúmeras fotocopiadoras existentes, seja em bibliotecas ou centros de ensino e pesquisa (escolas e universidades), estabeleceu-se um mercado decorrente, muitas vezes, no qual esqueceu-se da preservação dos direitos autorais implícito em cada documento fotocopiado e ou duplicado na clandestinidade. Sem pensar em restituir os respectivos direitos oriundos do trabalho intelectual.
Certamente, o mundo digital possibilita exponenciar a duplicação de documentos e enviá-los instantaneamente para lugares que ainda existem barreiras geográficas, mas facilitou imensamente eliminando ou pelo menos diminuindo as barreiras de acesso à informação.

O uso educacional de determinada obra intelectual não significa dar respaldo ao uso piratateado. Acesso e uso necessitam serem repensados em ambientes online. Mas excluir ou não possibilitar o acesso à informação, seja de uma obra (impressa ou digital) em uma biblioteca tradicional ou consultá-la pela Internet repercute diretamente no direito de livre acesso à informação.

E, considerando que a informação, indiferente do suporte em que se encontre, implica diretamente na formação do cidadão, cabe aos bibliotecários juntar-se a essa discussão a ser realizada entre autores, entidades publicadoras e distribuidoras, e os diferentes públicos alvo (estudantes, professores, pesquisadores ou qualquer pessoa) na busca de meios de operacionalizar e tentar solucionar as questões decorrentes do direito ao acesso à informação.

É de fundamental importância, seja na disponibilização ou na disseminação da informação, que em ambientes educacionais, políticos, culturais, científicos e tecnológicos seja imprescindível à observação das leis, acordos, licenças e contratos estabelecidos entre os órgãos de publicação, autor(es), distribuidoras, bibliotecas, entre outros. Somente considerando e respeitando os direitos e deveres pertinentes a cada órgão envolvido no fluxo da informação poderá ser dinamizado o estabelecimento de diretrizes para o gerenciamento e planejamento de serviços, recursos e produtos em bibliotecas no suporte informacional à comunidade de usuários. 


\section{LIBERDADE DE ACESSO À INFORMAÇÃO}

Cada vez mais o acesso à informação torna-se vital para que o indivíduo interaja na sociedade e possa se realizar como cidadão.

Necessitam-se políticas públicas de acesso à informação, bem definidas, para evitar-se um caos social, decorrente da exclusão do acesso de milhares de pessoas ao mundo da informação.

No Brasil, como em outras nações, convive-se com diferentes categorias de analfabetos seja da escrita (da palavra), funcionais e tecnológicos. $\mathrm{E}$ consequentemente surgem questões de como enfrentar esta realidade para que todos sejam beneficiados pelo uso da informação.

Blattmann (2000) menciona que uma das possíveis respostas seria através da disponibilização, do acesso e uso da informação, indiferentemente se está impressa (papel), em bits (CD-ROM, páginas Web) em ondas sonoras (rádio), em imagens em movimento e sons (televisão, vídeo), etc. Desencadeando desta forma uma avalanche de perguntas sobre:

- como e onde o indivíduo pode acessar as diferentes fontes de informação?

- quais são estas fontes disponíveis pelas novas mídias?

- qual o papel do Estado e da sociedade para disponibilizar o acesso à informação?

- por onde começar, a quem atender e quais os fatores implícitos nas diferentes formas de alfabetização (da palavra, funcional e/ou tecnológica)?

Entre os enfoques nos quais se pode direcionar na busca de respostas desejadas e possíveis, são apontadas algumas idéias no documento coordenado por Miranda et al. (2000), ressaltando que as "formas de atuação do Estado com relação aos elementos estruturais da Sociedade da Informação são cruciais, uma vez que suas políticas podem traçar o horizonte e definir os modos de interação dos indivíduos, grupos, organizações e instituições públicas e privadas, tanto no interior do Estado quanto fora de seus limites institucionais."

Compete ao Estado um papel de destaque na elaboração de Políticas Públicas de acesso à informação. Ao pensar-se nesse Brasil, país cheio de contrastes, com problemas que envolvem as estruturas da sociedade e abalam seriamente a questão do acesso à informação decorrentes da existência da miséria e da pobreza. Essa pobreza que atinge cerca de $32 \%$ da população brasileira, em 1998. Essa realidade nua e crua é lastimável e isto afeta a sociedade na íntegra.

São estes milhares de brasileiros, que passam pela fome - sob enfoque da necessidade fisiológica, debatem-se no cotidiano para sobreviver, estão muitas vezes distantes de reconhecer a importância da informação, que ao acessar a informação poderiam tornar-se competitivos (no sentido de eficazes).

Ao comparar com os dados referente a Internet, somente cerca de 5\% da população brasileira acessa, de alguma forma, imaginase quem são os incluídos e os excluídos do ciberespaço.

Para um país continental, com diferenças culturais enormes, necessita-se criar espaços para expor sua riqueza da diversidade, resgatar e prestigiar a pluralidade existente. E nesse ambiente é que a Internet torna-se um espaço criativo, ferramenta pela qual o indivíduo age e interage com seus pares; recicla seu conhecimento; e libera sua expressão.

Observa-se que isto ocorre em tantos cantos e de formas encantadoras. Se no início essa produção intelectual e cultural no ciberespaço era restrita ao ambiente acadêmico, agora pode-se verificar como a sociedade apropria dessa tecnologia e incorpora-a ao saber/fazer.

Considerando-se que ainda algumas pessoas tem dificuldades de entender $o$ significado do ponto BR (.br), confundindo 
com as BRs (qual é e onde está este ponto nas rodovias brasileiras que cruzam o país de Norte a Sul), imagina-se o que se passa quando forem decifradas as ramificações .COM., .ORG, .GOV, .EDU, .MIL e tantas outras que serão utilizadas no cotidiano de quem trafega nas redes de computadores. Além do mais, as constantes mudanças de diretórios e subdiretórios, nomes de arquivos e suas extensões, caracterizando as estruturas e os respectivos formatos digitais no ciberespaço podem ser difíceis de serem assimiladas por milhares de indivíduos que tem apenas 3 anos e meio em média de escolaridade básica.

Cabe enfatizar a colocação de Miranda et al. (2000) no sentido de resgatar a importância da Internet na sociedade brasileira:

No que se refere à democratização do acesso à informação e ao conhecimento, os arquivos, as bibliotecas, os museus e os centros de documentação cumprirão um papel estratégico em duas grandes áreas de atuação. $\mathrm{Na}$ primeira, como instituições sociais com a missão e vocação de intermediação que viabilizarão o acesso público, gratuito e assistido aos conteúdos da Internet aos indivíduos e comunidades não conectadas. Este papel será especialmente requisitado nas próximas duas décadas quando a grande maioria da população brasileira continuará desconectada. Na segunda área de atuação, estas instituições replicarão na Internet, inovando a partir do conhecimento e experiência acumulada na função de operar coleções de conteúdos organizados segundo metodologias e padrões de seleção e qualidade visando o seu acesso democrático e a sua preservação para a as gerações futuras.

Certamente as unidades de informação necessitam: repensar a sua missão abrangendo as informações disponibilizadas em redes de computadores; e, prover mecanismos de acesso as coleções digitais. Estas coleções devem abranger aos aspectos quantitativos e qualitativos da produção artística, técnica e científica online. Será importante estabelecer qual(is) o(s) repertório(s) que armazenará(ão) toda produção intelectual registrada no país e preservará(ão) os conteúdos estrategicamente, considerando as mudanças de formatos digitais que possam existir, que muitas vezes impossibilitam o acesso público aos conteúdos existentes decorrentes da incompatibilidade de aplicativos seja de software ou de hardware.

Pode-se dizer que as novas tecnologias alteram profundamente o comportamento do ser humano na sociedade da informação. Utilizando-se de técnicas que são oriundas das necessidades e cada tecnologia tem sua história social - educacional - política e econômica. Nesse envolvimento do indivíduo com as tecnologias, observa-se que as mesmas vão se desdobrando, conforme as necessidades dos respectivos sujeitos. Enquanto que as bibliotecas necessitam de utilizar técnicas e tecnologias para atender a sua missão. Repensando isto numa sociedade onde a informação trafega em redes de computadores, conhecida como o ciberespaço.

Observa-se um novo horizonte que surge neste presente momento. É uma nova forma de atuação, de mudanças profundas que afetam a estrutura organizacional, o ambiente em rede de computadores precisa estar adequado (instalações: fibra ótica, 
computadores, softwares), o perfil dos bibliotecários preciso (saber utilizar o ambiente "novo", planejar, criar e manter serviços qualitativos para a função básica daquela biblioteca), categorizar os tipos de serviços que estas "novas" bibliotecas oferecem, para atender um usuário diferente (que interage instantaneamente utilizando as redes de computadores).

Este usuário necessita que sejam oferecidos produtos e serviços de informação qualitativos. Mas, devido a dinâmica existente, no ciberespaço, cabe lembrar que esse usuário muda sua relação de freguês e passa a ser cliente. Isto significa, que ele não só consome os produtos e serviços oferecidos, mas ele também contribui e cria novos produtos e serviços (interage).

Portanto resgata-se a importância do sujeito, o centro da atenções está no indivíduo, detentor de decisões próprias e responsável pela diferentes maneiras que se apropria da tecnologia (pelos diferentes recursos disponíveis na Internet), e possibilita novas e diferentes formas de interação.

Mas, necessita-se também de ações que preservem a privacidade do sujeito e possibilitem o acesso do produto intelectual coletivo organizado para salvaguardar e garantir os direitos dos envolvidos (autores e usuários) no processo da comunicação online vinculada nos canais formais nas redes de computadores.

Algumas iniciativas desta natureza, podem ser vistas como a desempenhada pelo Conselho Nacional de Desenvolvimento Científico e Tecnológico - CNPq, que oferece o apoio e a orientação necessários à comunidade científica, no País ou fora dele, criar meios para orientar sobre os requerimentos básicos, sua instrução, protocolo, acompanhamento e custeio da propriedade intelectual. A assistência oferecida além de orientar a formulação de pedidos de proteção, acompanha a colocação de produtos no mercado, participando da negociação e do disciplinamento contratual. (Brasil, 2000)

Outro exemplo, apresentado pelo Ministro Humberto Couto, do Tribunal de Contas da União, em Plenário Relatório de Auditoria da SECEX-SC, sobre pesquisa e desenvolvimento de projetos na Universidade Federal de Santa Catarina - UFSC, menciona o Diretório dos Grupos de Pesquisa do CNPq, e relaciona a regulamentação jurídica aplicável à criação e a propriedade intelectual, aos direitos autorais e ao patenteamento de produtos e processos, no âmbito das instituições de ensino superior. (Brasil, 2000)

A decisão de escolha sobre espaços de onde e como armazenar e disponibilizar as diferentes publicações online, tais como os grandes provedores de acesso e de conteúdo devem ser debatidas para entender a abrangência do fato de liberar documentos online. $\mathrm{O}$ agir local e pensar global ganha seu ponto crítico no mundo das redes de computadores. Se até pouco tempo tinha-se uma visão parcial do que existia nos diferentes repertórios (armazéns) de informação em seus diferentes suportes (impresso, fitas de vídeo, mapas, CD-ROMs, etc.), agora no mundo digital online existe um contraste sobre a complexidade superficial que aparenta o iceberg chamado informação online. Tudo isso necessita de debate intenso e urgente pela classe bibliotecária. A definição de políticas sobre os diferentes repertórios devem ser direcionados, pensando em resgatar informações que necessitam ser mantidas nesses repositórios, como diretriz preliminar pensar em soluções que extrapolem a vida humana. Assim, a questão torna-se cada vez mais, e a decisão de escolher provedores locais ou internacionais, tais como o Yahoo (http://www.yahoo.com), Yahoo Brasil (http://www.yahoo.com.br), Biblioteca Nacional (http://www.bn.br), e Rocket Library (http://rocket-library.com) necessitam ser consideradas em diferentes níveis: estratégicos, tácitos, operacionais. E o 
bibliotecário deverá participar ativamente no processo de decisão sobre políticas. E as escolas de Ciência da Informação, Biblioteconomia, Arquivística e Museologia necessitam estar envolvidos nessas políticas de preservação e de acesso a informação digital online.

Portanto, a rede de computadores possibilita inúmeras formas de interação do sujeito para inúmeros outros parceiros nesta jornada no ciberespaço. Conhecer o que existe nestes novos ambientes da informação online e principalmente preservar os direitos pessoais, são iniciativas que mostram a possibilidade de criar e estabelecer novos horizontes, oriundos da interação entre as pessoas. Observa-se que no final, todos são participantes e responsáveis desse resultado: um lugar melhor para se viver. Um cidadão que pensa no global mas age e interage no local.

\section{CONSIDERAÇÕES FINAIS}

Compete a classe bibliotecária participar intensamente nos debates e atuar na elaboração de políticas governamentais sobre a preservação e o acesso à informação, direitos autorais, propriedade intelectual e licenças de uso..

É fundamental que as unidades de informação promovam o acesso e disponibilizem os meios de acesso à informação digital: desde equipamentos conectados a Internet, recursos para imprimir e salvar as pesquisas, oferecer espaços para que o indivíduo possa acessar qualquer informação, seja ela digital ou não, e com isto espera-se que o conhecimento seja a mola propulsora de uma sociedade digna e próspera.

Os fatores de acesso e promoção aos diferentes processos de leitura e da alfabetização da palavra, funcional e tecnológica devem ser uma constante nos debates profissionais, bem como, na formação de novos bibliotecários e também na educação continuada dos mesmos.
A Internet, considera a mais nova mídia da comunicação, possibilita a interação plena do sujeito. Resultando na participação ativa no processo de comunicação. Deixa-se a posição de um leitor passivo para um próativo. E as tecnologias utilizadas nas redes de computadores podem ser utilizadas para disseminar idéias, criar novas percepções e recriar saberes.

É de fundamental importância, que o bibliotecário esteja acompanhando a evolução tecnológica e assumir a posição de mediador da informação nos diferentes ambientes, seja nas bibliotecas públicas, escolares, especializadas.

\section{FONTES DE REFERÊNCIA}

BLATTMANN, Ursula. As novas mídias eletrônicas e o acesso e uso da informação no ensino fundamental e médio: TV Escola, Sistemas de informação, redes. (Trabalho apresentado no 19. Congresso Brasileiro de Biblioteconomia e Documentação, 3. Congresso LatinoAmericano de Biblioteconomia e Documentação, 7. Encontro Nacional de Informação e Documentação Jurídica, realizado em Porto Alegre - Rio Grande do Sul, entre 24 a 30 de setembro de 2000) Disponível em: <http://www.ced.ufsc.br/ ursula/papers/ursul a_CBBD.html>

BRASIL. Ministério da Ciência e Tecnologia. Conselho Nacional de Desenvolvimento Científico e Tecnológico - CNPq. Propriedade Intelectual. Disponível em: $<$ http://www.cnpq.br/propriedade/index.htm\# apres. Acesso em: 26 out. 2000.

CIBERÉTICA. SIMPÓSIO INTERNACIONAL DE PROPRIEDADE INTELECTUAL, INFORMAÇÃO E ÉTICA, 1, 1998 Anais eletrônicos ... Florianópolis. Disponível

em: 
<http://www.ciberetica.iaccess.com.br/portug ues/anais.htm>. Acesso em: 14 out. 2000.

FREY, Kelly L. Business models and pricing issues in the digital domain. Journal of Library Administration, v. 24, n.4, p. 2737, 1997.

HARPER, Georgia. Copyright Law for Distance Learning. Office of General Counsel, University of Texas System. 1999. Disponível em: $<$ http://www.utsystem.edu/OGC/ IntellectualProporty/distance.htm $>$. Acesso em: 21 jul. 1999.

HOESCHL, Hugo Cesar. O impacto social da tecnologia na informação jurídica. Palestra apresentada no Painel Biblioteconomia em Santa Catarina, 19., Fórum Estadual de Informação Jurídica de Santa Catarina, 1. Florianópolis 01. dez. 2000 .

MARTINS FILHO, Plínio. Direitos autorais na Internet. Ciência da Informação, Brasília, v. 27, n. 2, p. 183-188, maio/ago. 1998.

MIRANDA, Antônio Lisboa Carvalho de (Coord.) et al. Os Conteúdos e a Sociedade da Informação no Brasil DataGramaZero Revista de Ciência da Informação, v.1 n.5, out. 2000 (artigo 03). Disponível em: < http://www.dgz.org.br/Atual/Art_03.htm>. Acesso em: 24 out. de 2000.

UNITED STATES COPYRIGHT OFFICE. The Library of Congress. Report on copyright and digital distance education: a report of the register of copyrights.1999. Disponível em: <http://lcweb.loc.gov/copyright/cpypub/de_rp rt.pdf>. Acesso em: 09 ago. 1999.
Ursula Blattmann

Professora no Curso de Biblioteconomia da Universidade Federal de Santa Catarina E-mail: ursula@ced.ufsc.br Gregório Jean Varvakis Rados Professor no Curso de Biblioteconomia e no Programa de Pós-graduação em Engenharia de Produção Universidade Federal de Santa Catarina E-mail: grego@ced.ufsc.br 